\title{
STUDI EKSPERIMENTAL KEAUSAN KUNINGAN MENGGUNAKAN PIN-ON-DISC TIPE POINT CONTACT
}

\author{
Imam Syafa'at", Adi Nurman, Darmanto \\ Jurusan Teknik Mesin, Fakultas Teknik, Universitas Wahid Hasyim Semarang \\ Jl. Menoreh Tengah X/22, Sampangan, Semarang 50236 \\ *Email: imamsyafaat@unwahas.ac.id
}

\begin{abstract}
Abstrak
Keausan adalah hilangnya materi yang timbul sebagai akibat interaksi mekanik dua permukaan yang saling bergesekan dan dibebani, maka akan terjadi keausan, atau perpindahan materi. Kontak yang terjadi antara dua benda dapat berupa titik (point), garis (line), ataupun elips. Analisis keausan dapat dicari menggunakan beberapa metode diantaranya dengan hasil perhitungan secara analitik dan hasil penelitian secara eksperimental. Tribometer pin-on-disc adalah alat uji untuk mengetahui kedalaman dan volume keausan. Penelitian ini bertujuan untuk mengetahui keausan bola kuningan yang digesekkan dengan disc. Material untuk pin terbuat dari kuningan dan disc terbuat dari baja. Pembebanan yang digunakan adalah 6, 8, dan $10 \mathrm{~N}$. Variasi waktu yang digunakan adalah 2,4,8, dan 16 menit. Hasil dari penelitian ini pada pembebanan $10 \mathrm{~N}$ pada jarak sliding 180,48 $m$ hasil keausannya adalah 3,047E-05 m. Volume keausan pada jarak 180,48 m dengan pembebanan $10 \mathrm{~N}$ hasil volume keausannya adalah 2,165E-11 $\mathrm{m}^{3}$. Semakin bertambah pembebanan dan jarak sliding maka nilai keausan semakin bertambah.
\end{abstract}

Kata kunci: Keausan, pin-on-disc, point contact

\section{PENDAHULUAN}

Salah satu faktor yang mempengaruhi umur pakai sebuah mesin adalah adanya gesekan satu sama lain yang terjadi bila komponen-komponen dalam permesinan saling kontak, sehingga menimbulkan adanya pengikisan permukaan komponen. Pengikisan atau dalam kata lain disebut sebagai keausan. Keausan inilah yang menjadi salah satu faktor utama terhadap umur dari komponenkomponen dalam permesinan (Stachowiak, 2005). Gesekan antar permukaan juga akan menimbulkan panas yang juga mempengaruhi keausan, karena dalam kajian material disebutkan bahwa kekerasan material akan berkurang seiring meningkatnya temperatur. Dampak dari gesekan antara dua material bisa dikurangi dengan memberikan pelumasan pada permukaan benda yang mengalami kontak (Solichin, dkk. 2012).

Krisnandi, dkk. (2012) melakukan penelitian studi eksperimen pengaruh beban terhadap koefisien gesek yang terjadi pada fase running-in pada material alumunium dan kuningan dengan menggunakan tribometer pinon-disc. Dari hasil pengujian didapatkan koefisien gesek pada fase running-in akan menurun sejalan bertambahnya jarak sliding sampai fase steady-state dan akan memiliki nilai koefisien yang hampir sama. Besarnya koefisien gesek pada fase running-in berbanding lurus dengan besarnya beban yang diberikan (gaya normal). Besarnya koefisien gesek pada material kuningan lebih besar dibanding dengan gaya gesek yang timbul pada alumunium. Untuk beban dan kecepatan yang sama, fase running-in pada alumunium lebih singkat dari pada yang terjadi pada kuningan. Fase running-in pada alumunium terjadi sampai \pm 40 detik (6 7 putaran), sedangkan untuk kuningan pada 70 detik (11 12 putaran).

Burhanudin, dkk. (2012) melakukan penelitian studi eksperimen pengaruh beban terhadap perubahan koefisien gesek pada rolling contact dengan tribometer pin on disc fase running in, Dari hasil pengujian didapatkan gaya gesek yang timbul pada kuningan lebih besar dibanding dengan gaya gesek yang timbul pada alumunium. Demikian pula koefisien gesek pada kuningan lebih tinggi dibanding pada alumunium. Fase running-in yang terjadi pada kuningan lebih lama $( \pm 340$ second $)$ dibanding fase running-in pada alumunium $( \pm$ 210 second).

Saputra (2010) melakukan penelitian perhitungan keausan pin pada sistem kontak sliding pin on disc menggunakan metode analitik dan metode elemen hingga, Pada penelitian ini ditunjukkan hasil perbandingan antara metode analitik dan metode elemen 
hingga dalam prediksi keausan. Hasil menunjukkan perbandingan GIWM Hegadekatte dengan GIWM Present terdapat perbedaan rata-rata sekitar $15,36 \%$, perbandingan antara FEM Hegadekatte dengan FEM present terdapat perbedaan rata-rata sekitar 2,69\% dan perbandingan antara GIWM Present dengan FEM present terdapat perbedaan rata-rata sekitar 6,58\%.

Hasry dan Kaelani (2014) melakukan penelitian studi eksperimental keausan permukaan material akibat adanya multi directional contact friction. Hasil dari penelitian menyebutkan bahwa gesekan banyak arah (Multi-Directional Friction) akan menghasilkan keausan yang lebih besar dibanding gesekan satu arah (Uni-Directional Friction). Material yang mengalami gesekan banyak arah dengan pembebanan statis sebesar $39.2 \mathrm{~N}$ dan dengan kecepatan sesaat yang berubah-ubah mulai dari nol sampai 19.546 $\mathrm{m} /$ menit, akan mengalami keausan dengan mekanisme abrasi. Berdasarkan penelitian diketahui juga bahwa adanya pelumas memberi pengaruh yang besar dalam mengurangi keausan.

Maulana (2012) melakukan penelitian tentang analisa keausan steady state pada kontak pin-on-disc dengan simulasi elemen hingga. Hasil pemodelan menunjukkan jari-jari kontak mengalami peningkatan seiring dengan bertambahnya jarak sliding. Pada tahap awal, peningkatan jari-jari kontak sangat tajam, kemudian mencapai kestabilan. Keausan yang terjadi juga meningkat tajam pada tahap awal kemudian mengalami kestabilan setelah menempuh jarak sliding 54629 mm. Komparasi FEM present model dengan model analitik GIWM Hegadekatte (2006) memperlihatkan kecenderungan serupa. Fenomena kestabilan aus ini memperlihatkan bahwa sistem telah berada dalam fase steady state setelah melewati running-in dalam aplikasi permesinan.

Pemodelan Keausan Steady State telah dilakukan oleh Syafa'at (2010). Pemodelan analitik keausan steady state memperlihatkan laju keausan telah konstan pada kisaran 2,44E$08 \mathrm{~mm} / \mathrm{mm}$ dengan fluktuasi dibawah $15 \%$ yang tidak berubah pada peningkatan jarak sliding $(s)$ fase steady state dimulai pada $s=$ $80405 \mathrm{~mm}$. Pemodelan FEA menghasilkan tekanan kontak $(p)$ yang telah konstan pada kisaran 63,82 Mpa dengan fluktuasi dibawah $2 \%$ dan laju keausan yang stabil sebesar 1,72E$08 \mathrm{~mm} / \mathrm{mm}$ dan fluktuasi dibawah $2 \%$. Fase steady state dimulai pada $s=80405 \mathrm{~mm}$. Hasil Validasi pemodelan dengan eksperimen memperlihatkan permukaan telah konformal dengan perbandingan radius awal dan radius akhir sebesar 0,0566 mulai jarak sliding $(s)$ $72000 \mathrm{~mm}$.

Penelitian ini secara garis besar berisi tentang analisa keausan point contact secara analitik menggunakan pemodelan Global incremental wear model (GIWM) oleh Hegadekatte (2006). Tujuan penelitian ini adalah Mengetahui diameter keausan, tinggi keausan dan volume keausan pin.

\section{METODOLOGI PENELITIAN}

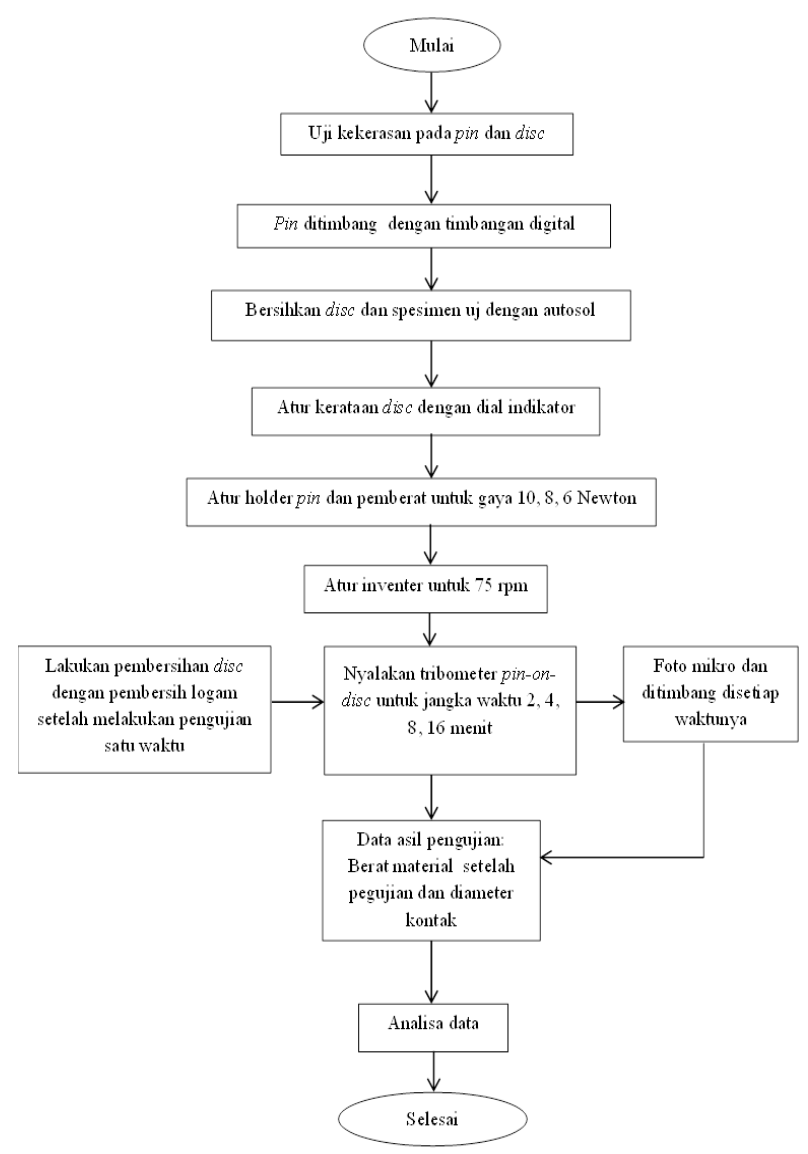

\section{Gambar 1. Diagram alir penelitian}

Adapun urutan dari penelitian ini seperti terlihat pada Gambar 1. Prosedur dan langkah penelitian meliputi beberapa tahapan. Pertama uji kekerasan material kemudian menimbang berat dari pin yang akan diuji, lalu disc dan pin dibersihkan dengan menggunakan Autosol. Pada tahap selanjutnya mengatur kerataan disc dengan dial indikator kemudian atur holder pin dan pemberat dengan gaya $10 \mathrm{~N}, 8 \mathrm{~N}$ dan $6 \mathrm{~N}$. Kemudian atur frekuensi $2,5 \mathrm{~Hz}$ pada inverter. 
Lakukan pembersihan disc dengan pembersih logam setelah pengujian satu waktu. Tahap berikutnya nyalakan tribometer pin-on-disc untuk jangka waktu 2, 4, 8 dan 16 menit. Kemudian foto mikro dan ditimbang setelah satu pengujian. Dilanjutkan pada tahap pembahasan dan pelaksanaan metode analitik dan metode eksperimen.

\section{Tribometer pin-on-disc}

Keausan pada point contact dapat diketahui dengan melakukan eksperimen. Alat yang digunakan untuk eksperimen adalah tribometer pin-on-disc, seperti yang terlihat pada Gambar 2, cara kerja alat ini adalah sebuah pin diberi beban terhadap piringan datar (disc), kemudian disc diputar dengan motor yang diatur kecepatannya menggunakan inverter dan diatur dengan kecepatan konstan. Untuk mengetahui diameter aus pada pin pengukuran dilakukan empat kali dengan menggunakan foto mikro pada setiap spesimen yaitu pada menit ke 2, 4, 8 dan 16. Parameter yang dapat digunakan bervariasi antara ukuran dan bentuk pin, beban, kecepatan, dan material.

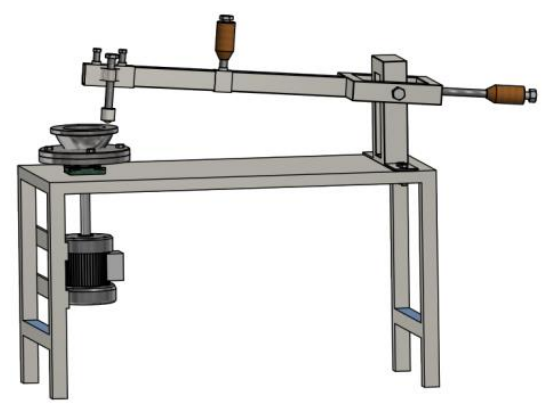

Gambar 2. Tribometer pin-on-disc

\section{Material dan ukuran bahan}

Tabel 1. Spesifikasi pin dan disc

\begin{tabular}{lllll}
\hline Kontak & $\begin{array}{l}\text { Bentuk } \\
\text { Pin }\end{array}$ & Ukuran & Bahan & Kekerasan \\
\hline $\begin{array}{l}\text { point } \\
\text { contact }\end{array}$ & bola & R-7,425 & kuningan & 70 HRB \\
\hline Disc & & $\begin{array}{l}\text { Diameter } \\
90.10-3\end{array}$ & $\begin{array}{l}\text { Baja AISI } \\
52100\end{array}$ & 55 HRC \\
\hline
\end{tabular}

Untuk mengetahui pengaruh keausan secara makroskopis maka material yang digunakan adalah seperti dalam tabel 1 . Pengujian dilakukan menggunakan tiga spesimen dengan pembebanan $10 \mathrm{~N}, 8 \mathrm{~N}$, dan 6 $\mathrm{N}$. Untuk mengetahui ukuran diameter aus pada setiap spesimen dilakukan foto mikro pada menit ke 2, 4, 8, dan 16. Perhitungan keausan eksperimen menggunakan perhitungan dari Stachowiak (2005) seperti yang ditunjukkan pada Gambar 3.

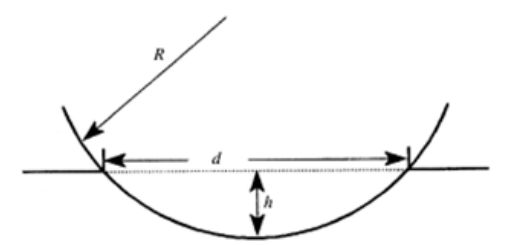

\section{Gambar 3. Diameter kontak keausan $(d)$ (Stachowiak, 2005)}

$$
h=\frac{D}{2}-\frac{1}{2}\left[D^{2}-d^{2}\right]^{1 / 2}
$$

Pada Pers. (1), $\mathrm{h}$ adalah tinggi keausan (m), D adalah diameter pin (m), dan d adalah diameter kontak keausan (m).

GIMW diterapkan pada kasus pin yang ujungnya berbentuk bola lunak yang kemudian disliding di atas sebuah piringan yang keras. Keausan yang terjadi pada pin lebih besar, sedangkan keausan pada piringan diabaikan. Karena proses keausan pada ujungnya berbentuk bola maka GIMW untuk menghitung keausannya berdasarkan pada hitungan secara berurutan mulai dari jari-jari kontak dan kemudian luas kontak.

$$
h_{p c}^{w}=\left(\frac{F_{N} k_{D} s}{\pi R_{p}}\right)^{\frac{1}{2}}
$$

Rumus di atas dipergunakan untuk menghitung keausan pin, dimana $h_{p c}^{w}$ adalah keausan point contact (kontak titik), $k_{D}$ adalah koefisien aus berdimensi, $F_{N}$ adalah beban, $R_{p}$ adalah radius pin, dan $s$ adalah jarak sliding. Klasifikasi nilai koefisien keausan $(\mathrm{kD})$ telah disajikan oleh Van Beek (2012). Koefisien keausan yang dipilih adalah $\mathrm{k}_{\mathrm{D}}=12 \cdot 10^{-15} \mathrm{~m}^{2} / \mathrm{N}$.

\section{HASIL DAN PEMBAHASAN}

Hasil perhitungan analitik GIWM dan eksperimen pin-on-disc adalah pada metode analitik GIWM pada pembebanan $10 \mathrm{~N}, 8 \mathrm{~N}$, dan $6 \mathrm{~N}$ pada jarak sliding 22,56 meter menghasilkan nilai keausan wear depth 1,077E-05 m, 9,638E-06 m, dan 8,346E-06 m. Pada metode eksperimen dengan pembebanan $10 \mathrm{~N}, 8 \mathrm{~N}$, dan $6 \mathrm{~N}$ pada jarak sliding 22,56 menghasilkan nilai wear depth $1,76 \mathrm{E}-05 \mathrm{~m}$, 1,15E-05m, dan 6,79E-06m. 
Foto mikro hasil eksperimen ditunjukkan pada Gambar 4, pada spesimen dengan pembebanan 6 Newton dengan jarak siding sekitar 22,56 meter, diameter kontak ausnya adalah $608,1 \mu \mathrm{m}$ dan seiring bertambahnya jarak sliding hingga pada jarak sliding 180,48 diameter kontak aus sebesar 1216,2 $\mu \mathrm{m}$.

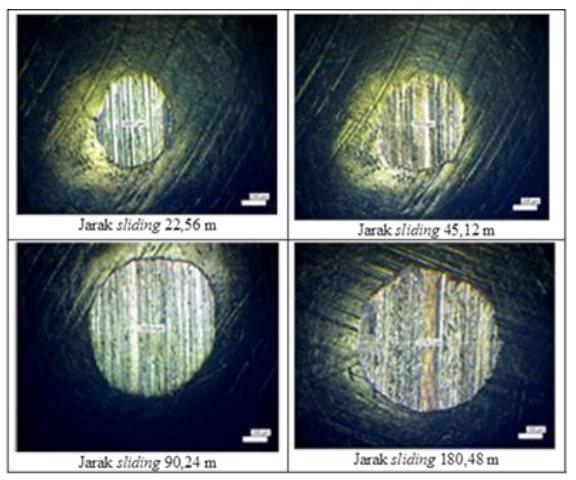

\section{Gambar 4. Foto Mikro pada spesimen} dengan pembebanan 6 Newton

Luas daerah kontak (A) di didapatkan dari rumus lingkaran berdasarkan hasil diameter daerah kontak. Gambar 5 menunjukkan pada jarak sliding 22,56 m sampai dengan 180,48 m luas kontak area pembebanan $10 \mathrm{~N}, 6 \mathrm{~N}$ dan 8 $\mathrm{N}$ relatif naik. Pada pembebanan $10 \mathrm{~N}$ dengan jarak sliding 22,56 m luas kontak area sekitar $0,82 \mathrm{~mm}^{2}$ sampai pada jarak sliding 180,48 m luas kontak area sekitar $1,59 \mathrm{~mm}^{2}$. Pada pembebanan $8 \mathrm{~N}$ dan $6 \mathrm{~N}$ sama dengan pada pembebanan $10 \mathrm{~N}$ yaitu relatif naik. Hal ini disebabkan karena semakin bertambahnya jarak sliding dan diameter kontak aus maka luas kontak area semakin bertambah.

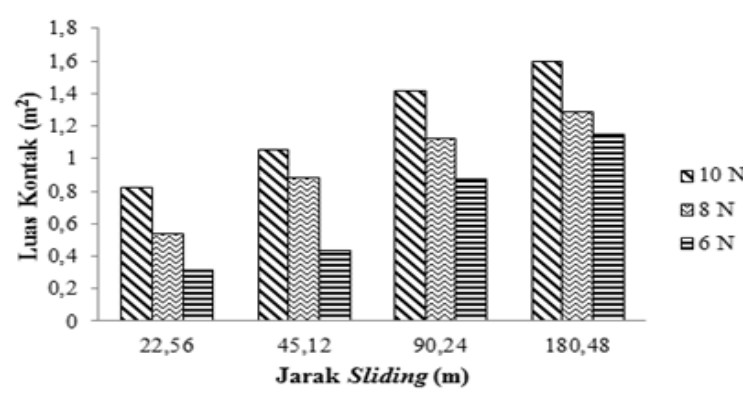

\section{Gambar 5. Luas daerah kontak hasil eksperimen pin-on-disc}

Tekanan kontak $(\mathrm{P})$ didapatkan dari gaya normal (F) dibagi luas daerah kontak (A) yaitu :

$$
\mathrm{P}=\mathrm{F} / \mathrm{A} \text {. }
$$

Gambar 6 pada jarak sliding 22,56 m sampai dengan 180,48 $\mathrm{m}$ tekanan kontak terus menurun. Pada pembebanan $6 \mathrm{~N}$ mempunyai nilai paling tinggi diikuti pembebanan $8 \mathrm{~N}$ dan pembebanan $10 \mathrm{~N}$ mempunyai tekanan kontak paling rendah. Pada pembebanan $6 \mathrm{~N}$ dengan jarak sliding 22,56 m tekanan kontak sekitar 18,9 Mpa sampai pada jarak sliding 180,48 m tekanan kontak sekitar 5,2 Mpa. Pada pembebanan $8 \mathrm{~N}$ dan $10 \mathrm{~N}$ sama dengan pada pembebanan $6 \mathrm{~N}$ yaitu tekanan kontak menurun. Hal ini disebabkan karena semakin bertambahnya jarak sliding dan luas kontak area maka tekanan kontak semakin menurun.

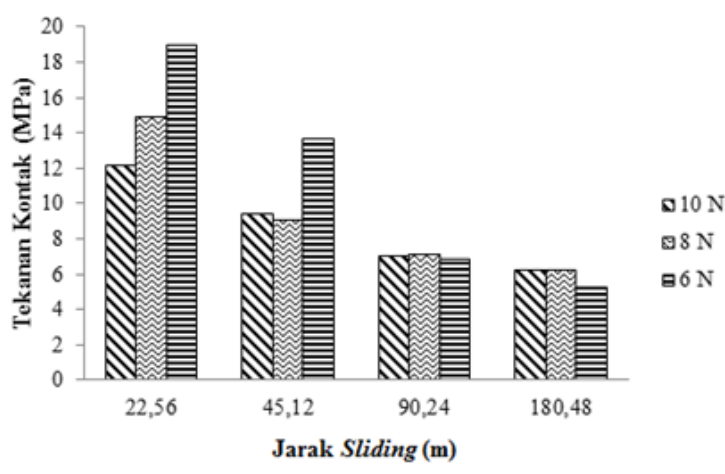

Gambar 6. Tekanan kontak pada eksperimen pin-on-disc

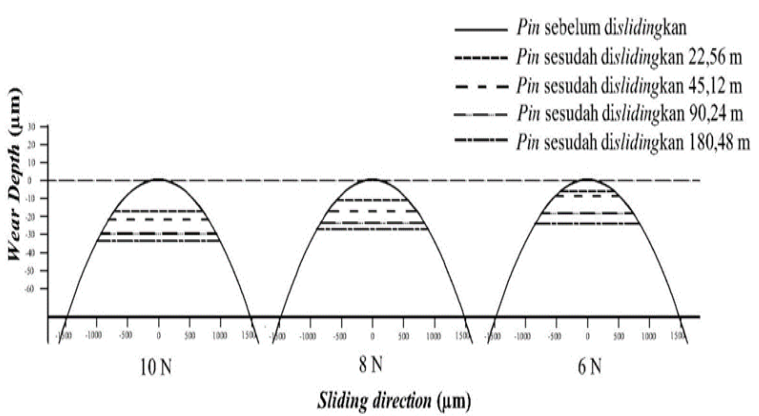

Gambar 7. Perubahan profil pin

Perubahan profil pin diilustrasikan pada Gambar 7 dari skema memperlihatkan pada pembebanan $10 \mathrm{~N}$ terlihat nilai wear depth di tiap waktunya menunjukkan paling tinggi dari pada pembebanan $8 \mathrm{~N}$ dan $6 \mathrm{~N}$. Pada awal sliding laju wear depth sangat cepat kemudian setelah menempuh jarak sliding 90,24 m semakin stabil.

Hasil eksperimen dan analitik GIWM setelah diplotkan pada Gambar 8 nilai wear depth hasil analitik dan eksperimen pada pembebanan $8 \mathrm{~N}$ dan $6 \mathrm{~N}$ hasil eksperimen hampir mendekati GIWM, dan pada 
pembebanan $10 \mathrm{~N}$ hasil eksperimen menjauh GIWM.

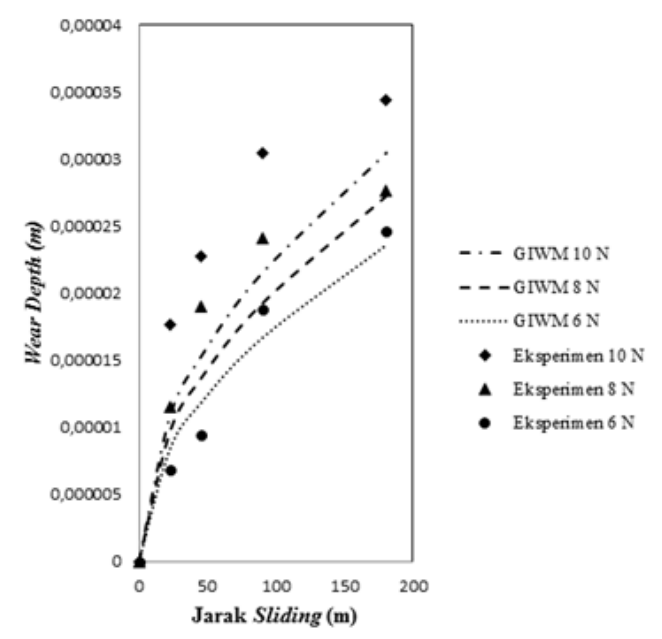

\section{Gambar 8. Grafik wear depth perbandingan GIWM dan eksperimen}

Pada eksperimen dengan pembebanan 10 $\mathrm{N}$ hasilnya menjauhi GIWM tetapi pada pembebanan $8 \mathrm{~N}$ dan $6 \mathrm{~N}$ hasil mendekati GIWM. Hal ini kemungkinan disebabkan karena material pin dari kuningan yang lunak digesekkan dengan disc yang keras sehingga pada beban besar keausannya lebih besar.

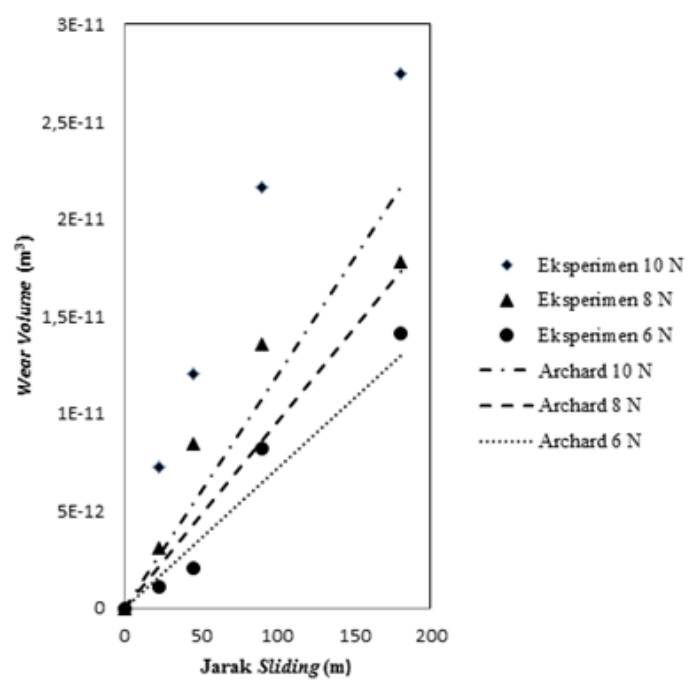

\section{Gambar 9. Grafik volume keausan perbandingan Archard dan eksperimen}

Nilai eksperimen mempunyai kecenderungan lebih tinggi pada perbandingan antara Archard dan eksperimen. Hal tersebut membuktikan seiring bertambahnya jarak sliding maka luasan kontak aus bertambah namun volume keausan semakin menurun.
Fenomena ini terjadi hampir sama pada tiga jenis spesimen dengan pembebanan 8 dan 6 Newton. Namun yang paling tinggi pada hasil eksperimen pembebanan $10 \mathrm{~N}$ seperti pada Gambar 9.

\section{KESIMPULAN}

Nilai keausan pada metode analitik dan eksperimen sama-sama berbanding lurus dengan pembebanan yaitu semakin bertambah pembebanan dan jarak sliding maka nilai keausan semakin bertambah. Nilai wear depth pada pembebanan 8 Newton dan 6 Newton hasil eksperimen hampir mendekati GIWM, dan pada pembebanan 10 Newton pada jarak sliding 180,48 m hasil eksperimen kurang akurat. Luas daerah kontak pada jarak sliding 22,56 m sampai dengan 180,48 $\mathrm{m}$ luas kontak area pembebanan $10 \mathrm{~N}, 6 \mathrm{~N}$ dan $8 \mathrm{~N}$ relatif naik.

Hal ini disebabkan karena semakin bertambahnya jarak sliding dan diameter kontak aus maka luas kontak area semakin bertambah. Tekanan kontak pada jarak sliding 22,56 m sampai dengan 180,48 m tekanan kontak terus menurun. Hal ini disebabkan karena semakin bertambahnya jarak sliding dan luas kontak area maka tekanan kontak semakin menurun.

\section{DAFTAR PUSTAKA}

Archard, J. F. (1953). Contact and rubbing of flat surfaces. J. Appl. Phys., 24, 981-988.

Burhanudin, A., Krisnandi, D., Armanto, E., Prabowo, D. (2012)., Studi eksperimen pengaruh beban terhadap perubahan koefisien gesek pada rolling contact dengan tribometer pin on disc fase running in, Prosiding SNST ke-3 Tahun 2012 Fakultas Teknik Universitas Wahid Hasyim Semarang. Hal D.23 - D.28.

Hasry, M., Kaelani, Y. (2014). Studi Eksperimental Keausan Permukaan Material Akibat Adanya MultiDirectional Contact Friction, Jurnal Fakultas Teknologi Industri, Institut Teknologi Sepuluh Nopember Surabaya. Hal B.108 - B.113.

Hegadekatte, V., Huber, N. and Kraft, O. (2005). "Development of a simulation tool for wear in microsystems", in Advanced Micro and Nano Systems Micro-engineering in Metals and Cramics Desigen Part II, ed. Löhe, D., Haubelt, J.H. Baltes, H., Brand, O., Fedder, G.K., Hierold, C., Korvink, J.G. 
and Tabata, O., Wiley-VCH Verlag $\mathrm{GmbH}$, Weinheim, Germany, 605-624.

Hegadekatte, V. (2006). Modelling and simulation of dry sliding wear for micromachine applications. $\mathrm{PhD}$ Thesis, University of Karlsruhe, Shaker Verlag, Aanchen, Germany.

Krisnandi, D., Burhanudin, A., Armanto, E., Prabowo, D. (2012). Studi eksperimen pengaruh beban terhadap koefisien gesek yang terjadi pada fase running-in, Prosiding SNST ke-3 Tahun 2012 Fakultas Teknik Universitas Wahid Hasyim Semarang. Hal D.18 - D 22.

Maulana, F.N. (2012). Analisa Keausan Steady state pada kontak Pin-On-Disc dengan simulasi elemen hingga. Tugas Akhir, Universitas Wahid Hasyim, Semarang. Hal 28 - 32.

Saputra, E. (2010). Perhitungan keausan pin pada sistem kontak sliding pin on disc menggunakan metode analitik dan metode elemen hingga, Tugas Akhir Teknik Mesin, Universitas Diponegoro, Semarang.

Solichin, M dan Kaelani, Y. (2012). Studi Eksperimental Laju Keausan (Specific Wear Rate) Antara Ultra High Molecular Weight Polyethylene (UHMWPE) Dengan Stainless Steel Sebagai Sendi Lutut Buatan (Total Knee Replacement Prosthesis) Manusia. Jurnal Fakultas Teknologi Industri Institut Teknologi Sepuluh Nopember Surabaya. Hal $1-5$.

Stachowiak, G.W. (2005). "Tribology in practice series", in Wear-Material, Mechanisms and Practice, John Wiley \& Sons Ltd, The Atrium, Southern Gate, Chichester, England.

Syafa'at, I. (2010), "Permodelan Keausan Steady State", Tesis Magister Teknik Mesin, Universitas Diponegoro, Semarang.

Van Beek, A. (2012). Advanced Engineering Design: Lifetime Performance and Reliability, TU Delft. Delft. 